\title{
Sobre fadas e confiança: Um ano de governo Macri
}

\author{
Alexandre Jerônimo de Freitas ${ }^{102}$ \\ Marcelo Fernandes ${ }^{103}$
}

\begin{abstract}
Resumo
O objetivo deste artigo é fazer uma análise da economia argentina no primeiro ano do governo Macri. Mostraremos que a propalada busca pela confiança, através medidas que reduzem o papel do setor público não alcançaram resultados favoráveis como previram as autoridades econômicas.
\end{abstract}

Palavras-Chave: Argentina, Confiança, Governo Macri

\begin{abstract}
The purpose of this article is to make an analysis of the Argentine economy in the first year of the Macri government. We will show that the much publicized quest for confidence, through measures that reduce the role of the public sector, did not achieve favorable results as predicted by the economic authorities.
\end{abstract}

Keywords: Argentina, Confidence, Macri Government

JEL Classification: E12; E22; E63

\section{Introdução}

A estratégia econômica que ajudou na vitória de Maurício Macri à presidência da Argentina realçava uma necessidade de um "choque de confiança" para lograr taxas mais elevadas de crescimento. Nessa visão o Estado perderia o protagonismo em prol do crescimento dos investimentos do setor privado. Esse investimento seria financiado pela entrada de dólares na economia através de dois canais. Primeiramente, com o pagamento dos "Fundos Abutres", o risco-país se reduziria e a Argentina voltaria aos mercados financeiros internacionais. Por outro lado, a maior confiança no governo, reduziria a preferência pela liquidez em moeda estrangeira do setor privado, estimulando o retorno dos dólares investidos no exterior.

Soma-se a isso, a adoção de uma política de perdão das dívidas de depósitos ilegais no exterior também contribuiria para o financiamento do Investimento. $O$ crescimento do investimento pelo setor privado implicaria numa melhora da produtividade. Seria o início de um ciclo de crescimento sustentável, movido pela maior eficiência e competitividade da economia.

A estabilização monetária completaria o ambiente propício ao crescimento liderado pelo setor privado. A redução do papel do Estado na economia, com a diminuição nos gastos e emprego públicos, contribuiria para redução do déficit público e, por conseguinte, da emissão monetária, tida como a principal responsável pela inflação.

O objetivo deste artigo é analisar a economia argentina neste primeiro ano do governo Macri. Incialmente, discutiremos brevemente a questão da confiança. Posteriormente,

\footnotetext{
102 UFRRJ

${ }^{103}$ UFRRJ
} 
analisaremos as primeiras medidas econômicas. Os resultados de sua estratégia econômica neste primeiro ano serão apresentados em seguida. Por fim, algumas considerações finais concluem a análise.

\section{Confiança e Crescimento Econômico}

"Confidence is the cheapest form of stimulus"

Larry Summers

A conjuntura econômica argentina às vésperas da eleição de 2015 era instável. Após experimentar um período de crescimento elevado inédito em sua história, a economia passou a conviver com taxas menores de crescimento e com uma inflação elevada e persistente. Para a equipe econômica de Macri a estagnação era resultado do excesso de intervenção do Estado na economia. Sua redução criaria um bom ambiente de negócios para que o setor empresarial voltasse a investir. Tratava-se de promover um "Choque de Confiança" na economia.

A ideia do "choque de confiança" foi bastante debatida nos últimos anos pelos economistas através do termo "contração fiscal expansionista", em torno da qual discutia-se o papel da política fiscal e seus impactos no crescimento. Seus defensores afirmam que as medidas de austeridade fiscal embora afetassem negativamente a demanda devido à redução dos gastos do governo, contribuíram para aumentar a confiança da classe empresarial estimulando o investimento privado. Os impactos positivos sobre a confiança mais que compensariam os impactos negativos da política fiscal contracionista. ${ }^{104}$

Esta estratégia começaria pela restrição aos gastos públicos. Na medida em que o investimento público se retraísse, haveria menor competição pela poupança disponível elevando a oferta de recursos para o setor privado. A menor competição também reduziria as taxas de juros na economia, barateando os custos de financiamento com efeitos positivos sobre o investimento e o crescimento.

Outro impacto positivo para a construção da confiança é que a redução de gastos do governo reduziria a expectativa de necessidade futura de elevação dos impostos pelos agentes econômicos, o que estimularia as decisões de investimento. Além disso, a geração de superávits primários contribuiria para reduzir o tamanho da dívida pública, afastando qualquer suspeita do setor privado sobre a possibilidade de default do governo.

A sustentabilidade do novo ciclo de crescimento liderado pelo investimento privado estaria garantida pelos efeitos positivos sobre o nível de competitividade e produtividade da economia proveniente da maior participação dos investimentos privados na composição total dos investimentos na economia.

Nos termos de Krugman ${ }^{105}$, os encantos da "fada da confiança" são menos apreciados pelos economistas keynesianos e pelo próprio Keynes. No fim da década de 1920, em meio a grave crise econômica que assolava a Inglaterra, Keynes escreveu em conjunto com Hubert Henderson, em apoio à candidatura de Lloyd George para as eleições de 1929, um panfleto em que defendia um programa de obras públicas como forma de reduzir o desemprego (Keynes, 1978).

Porém, mais tarde na Teoria Geral, Keynes também reconheceu a possibilidade de uma política fiscal expansionista gerar um "crowding-out psicológico" que inibiria o animal spirits enfraquecendo as decisões de investimento na economia:

\footnotetext{
${ }^{104}$ Ver King et al. (2012).

${ }^{105}$ http://www.nytimes.com/2010/07/02/opinion/02krugman.html
} 
"Dada a psicologia confusa que frequentemente prevalece, o programa do Governo pode, através de seus efeitos sobre a "confiança", aumentar a preferência pela liquidez ou diminuir a eficiência marginal do capital, o que também contribui para retardar outros investimentos se não houver medidas que o contrabalancem" (Keynes, 1936 [1996], p.138).

Mas lembremos que Keynes acreditava que seria isso seria bastante improvável. No período da crise, o debate sobre a maior participação do Estado e o estado de confiança da classe empresarial cerceava a política econômica do novo governo trabalhista vencedor das eleições. Em sua crítica ao May Report, relatório emitido em julho de 1931 pela Comissão de Gastos Nacionais, Keynes defendia a ideia de que os impactos positivos que um programa de gasto público teria no emprego e na renda ofuscariam quaisquer impactos negativos sobre o estado de confiança da classe empresarial. (Considini; Duffy, 2016).

$O$ investimento responderia então mais ao crescimento da demanda agregada do que ao estado de confiança da classe empresarial. A decisão de investir do empresário estaria relacionada à possibilidade de lucros futuros advindos do crescimento da demanda suficiente para absorver sua produção. A política econômica joga um papel decisivo na formação dessas expectativas.

Neste sentido, a despeito do impacto na confiança da classe empresarial, uma política fiscal contracionista afetaria negativamente a demanda agregada desestimulando novos investimentos do setor privado.

\section{0 "choque de confiança" do Governo Macri}

Para compreendermos melhor as medidas adotadas pelo governo a partir de 2016, faremos uma brevíssima descrição da conjuntura econômica argentina as vésperas da eleição presidencial de 2015.

Entre 2003-2011 a Argentina foi uma das economias que mais cresceram no mundo, muito acima de seus pares latino-americanos. Isto propiciou uma elevação no emprego, aumento da participação dos salários na renda com crescimento dos salários reais e redução dos níveis de desigualdade e dos índices de pobreza que haviam explodido quando da crise de 2001.

O crescimento da economia havia sido liderado por políticas voltadas ao mercado interno, que estimularam o consumo privado e os gastos públicos, incentivando o crescimento dos investimentos como um todo. Muitos analistas creditaram esta conjuntura a momento da economia internacional e ao crescimento das exportações. A economia argentina estaria se aproveitando do "viento de cola". Porém as exportações foram o elemento menos dinâmico da demanda, crescendo 6,25\% no acumulado entre 2003-2011. As exportações cumpriram um papel essencial não diretamente para o crescimento econômico, mas sim para a geração de divisas. O ponto negativo deste período foi o recrudescimento da inflação (Ver Gráfico 5). Ela teria sido alimentada pelo crescimento dos salários reais acima da produtividade entre 20032006 , aliadas aos choques de custos de 2007/2008 e 2010. Além disso, o conflito distributivo se acentuou após 2010. (Amico, 2013).

Mas a partir de 2011 a economia argentina perde dinamismo e passa a enfrentar um período de baixo crescimento e estagnação dos salários junto com persistência da inflação. Para Amico (2013), uma mudança na política macroeconômica após a reeleição de Cristina Kirchnner esfriou os mecanismos que sustentaram o crescimento no período anterior. Foram implementados aumentos graduais nos serviços públicos, foram limites para o crescimento de salários, restrições às importações e o controle cambial. A adoção de uma política fiscal mais restritiva, cujo objetivo era reduzir o déficit primário, estancou o consumo e investimento 
públicos impactando de forma negativa o investimento privado, a manutenção do emprego e da massa salarial, reduzindo o consumo das famílias.

\section{Montagem e operação de sua economia}

Mauricio Macri assumiu a presidência em 10 de dezembro de 2015, com a promessa de uma grande virada na política macroeconômica do governo Kichner. O principal mote de sua campanha estaria na retomada da confiança dos investidores, considerado ponto crucial para retomada do crescimento. Com isso, o governo Macri pretendia provocar um choque de mercado de forma a reduzir paulatinamente a inflação, interromper a saída de dólares e estimular o investimento privado.

Assim, logo na primeira semana de governo, Macri cumprindo promessa de campanha, eliminou o chamado "cepo cambial". Tratava-se de um conjunto de medidas adotadas pelo governo durante o segundo Governo da presidenta Cristina Kirchner (2011-2015) que visava reduzir o acesso ao mercado oficial de moeda estrangeira, se caracterizava por um rígido controle do câmbio sobre as importações e as remessas de rendas ao exterior (BCRA, 2016; Fanelli e Albrieu, 2015, p.7). Segundo o então ministro da Fazenda, Alfonso Prat-Gay “El que quiere comprar dólares los puede comprar, el que quiere vender, va a poder vender. Así funcionan las economías del mundo, nadie los va a perseguir" (Barreiro, 2016).

O fim do cepo veio acompanhado de uma maxidesvalorização do câmbio de $41,9 \%$. Visando beneficiar ainda mais o setor exportador, o governo reduziu o imposto à exportação ("retenciones") de soja de 35\% para 30\%, assim como para vários produtos agropecuários, industriais e minérios (Varesi, 2016, p.9). Com isso, somado à desvalorização cambial, as autoridades argentinas esperavam impulsionar as exportações, em particular do setor rural, algo que estava entre suas promessas de campanha.

Mais à frente, em janeiro de 2016, Macri reabriu o diálogo com os "fundos abutres" que há anos lutavam contra a Argentina nos tribunais em razão da moratória da dívida de 2002. Os fundos Elliot, Dart, AC Paster, Blue Angel NML Capital e Aurelius, que processavam a Argentina na justiça norte-americana, conseguiram em fevereiro de 2012 uma sentença favorável que mais tarde foi ratificada pela Câmara de Apelações dos EUA em 16 de junho (Kulfas, 2014).

Em março de 2016 o governo chegou a um acordo e, no mês seguinte, voltou a colocar no mercado financeiro internacional títulos do Tesouro Nacional e dos governos provinciais que garantiram a entrada de US\$16,5 bilhões a uma taxa média de 7, 2\% (BCRA, 2016). A entrada de recursos foi fundamental para pagar os "fundos abutres".

Em junho o governo aprovou um projeto de anistia fiscal para capitais não declarados de argentinos depositados no exterior ("blanqueo de capitales"). A medida visava repatriar fundos que estavam fora do país, que segundo o INDEC (2015b) estavam na ordem de US\$ 230 Bilhões. Ainda em junho, em um encontro com empresários espanhóis em Madri, Alfonso Prat-Gay, pediu desculpas "pelos últimos anos", se referindo principalmente a estatização da petroleira YPF, em 2012 que desde 1999 era controlada pela espanhola Repsol (Yebra, 2016). $O$ inédito pedido de desculpas institucional gerou constrangimento até entre os aliados do governo.

\section{Números e resultados}

Analisar o primeiro ano como um fracasso da estratégia econômica de um governo pode ser precipitado. Porém, no caso argentino, a análise se justifica pela estratégia adotada. 0 "choque de confiança", como o próprio nome diz, seria uma tática de curto-prazo para iniciar um processo de crescimento de médio e longo prazo. Ao final de um ano é possível avaliar através dos resultados se o choque surtiu efeito. 
Pelo Gráfico 1 percebe-se que, a despeito de uma eleição apertada, Macri inicia seu governo com um elevado nível de confiança $(3,14)$, comparável apenas ao de Nestor Kirchnner (3,26 em julho de 2003) e maior que o de Cristina Kirchnner (2,75 em janeiro de 2012). Mesmo assim, ao longo de seu primeiro ano, a confiança no governo foi diminuindo consecutivamente chegando ao seu nível mais baixo em fevereiro de $2017^{106}$. A imagem positiva do presidente Macri caiu de 63,2\% (janeiro de 2016) para 43\% (fevereiro de 2017) ${ }^{107}$

Gráfico 1: Índice de Confiança no Governo ${ }^{108}$

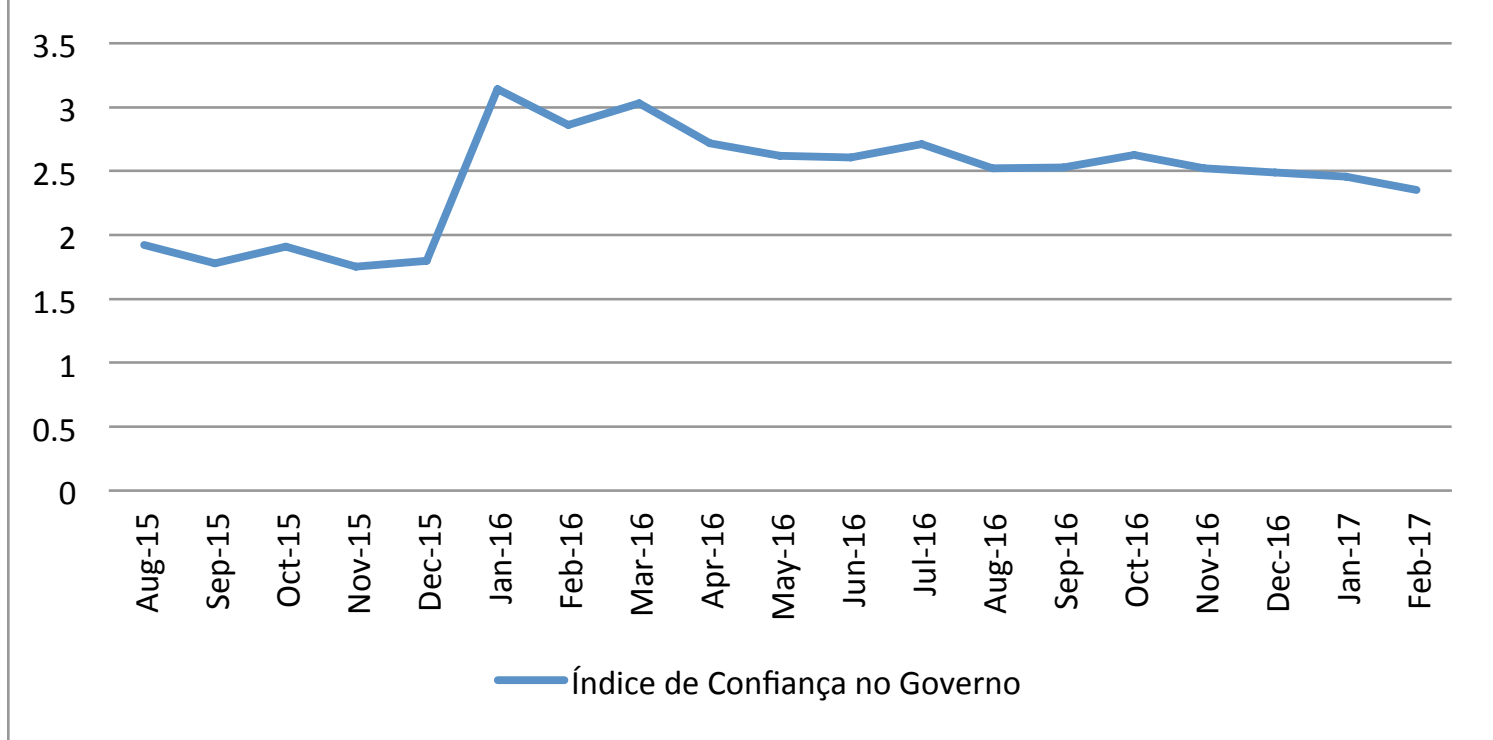

Fonte: Escuela de Gobierno (Universidade Torcuato di Tella)

O desempenho econômico argentino contribuiu para esta queda na avaliação no governo. A economia encontra-se em queda desde que a equipe econômica de Macri assumiu, entrando em recessão a partir do 2ㅇ trimestre de 2016.

Significativo para a estratégia de crescimento de longo prazo é a queda consecutiva da formação bruta de capital fixo. As medidas econômicas adotadas logo no início do governo fracassaram em estimular novos investimentos. Ademais, as famílias reduziram muito o consumo privado devido às perdas com a inflação e com o aumento nos preços da vários serviços públicos.

\footnotetext{
${ }^{106}$ Em pesquisa feita em Fevereiro de 2017, 41\% dos argentinos acreditam que a situação econômica irá piorar nos próximos meses. (http://www.ambito.com/873872-el-41-de-los-argentinos-evalua-queempeorara-la-situacion-economica-en-proximos-meses)

107 http://www.ambito.com/875325-encuesta-la-imagen-de-macri-cae-mas-de-20-puntos-en-un-anode-639-a-43

108 O ICG reflete a opinião dos argentinos a partir da estimação de 5 dimensões: (1) avaliação geral do governo, (2) percepção sobre se se governa pesando no bem geral, (3) eficiência da administração do gasto público, (4) honestidade dos membros do governo e (5) capacidade dos membros do governo para resolver os problemas do País. (Universidad Torcuato di Tella)
} 
Gráfico 2: Desempenho Econômico

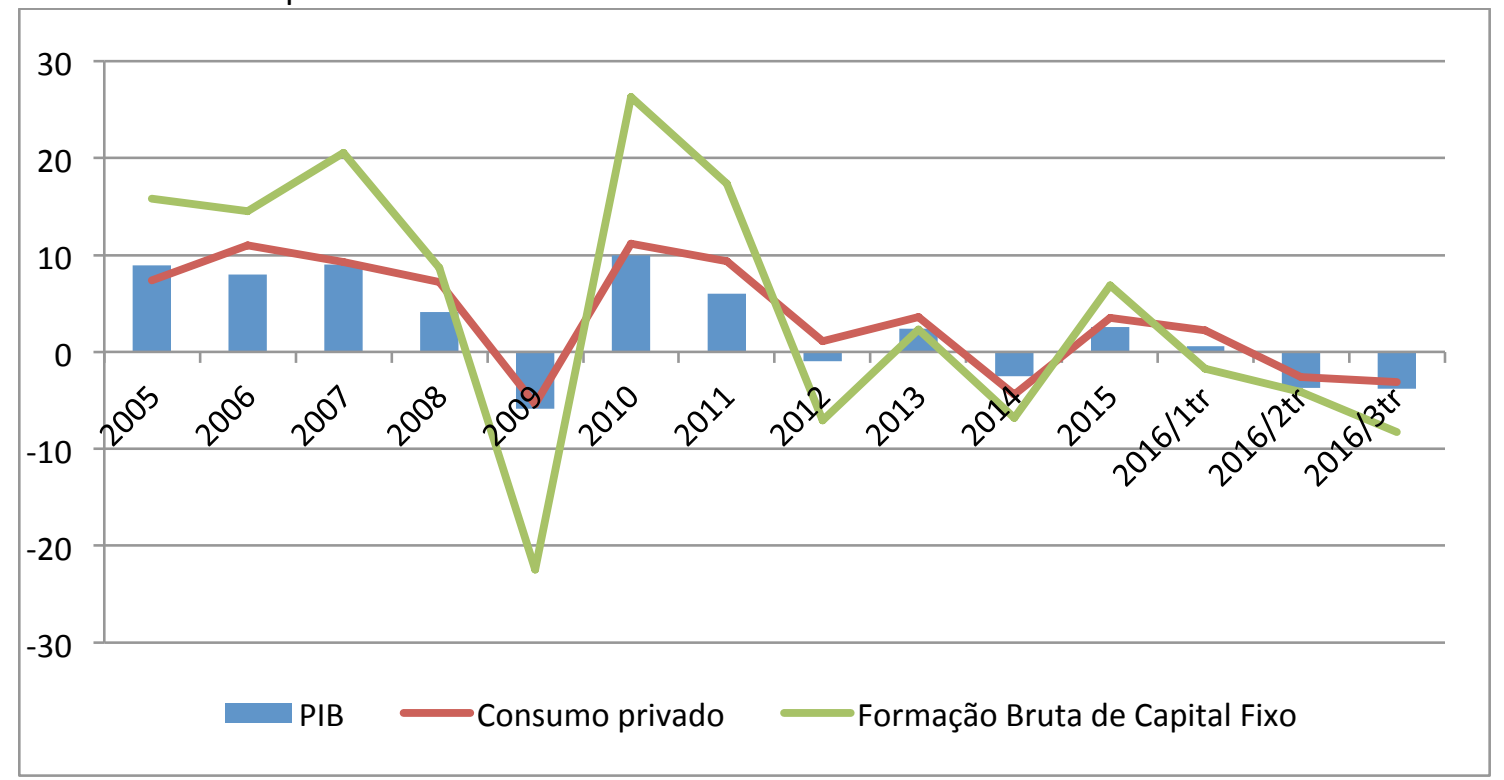

Fonte: INDEC. PIB (A Preços de 2004). Consumo e Formação Bruta de Capital Fixo (Variação em relação ao ano anterior)

Outro ponto no qual a prática se revelou distinta do plano econômico de Macri foi a entrada de dólares para o financiamento do investimento. O IED que havia se estabilizado no 1 으 trimestre de 2016 em comparação com o último de 2015, voltou a retomar a tendência de queda que apresentava durante 2015.

Gráfico 3: Investimento Externo Direto (Milhões de Dólares)

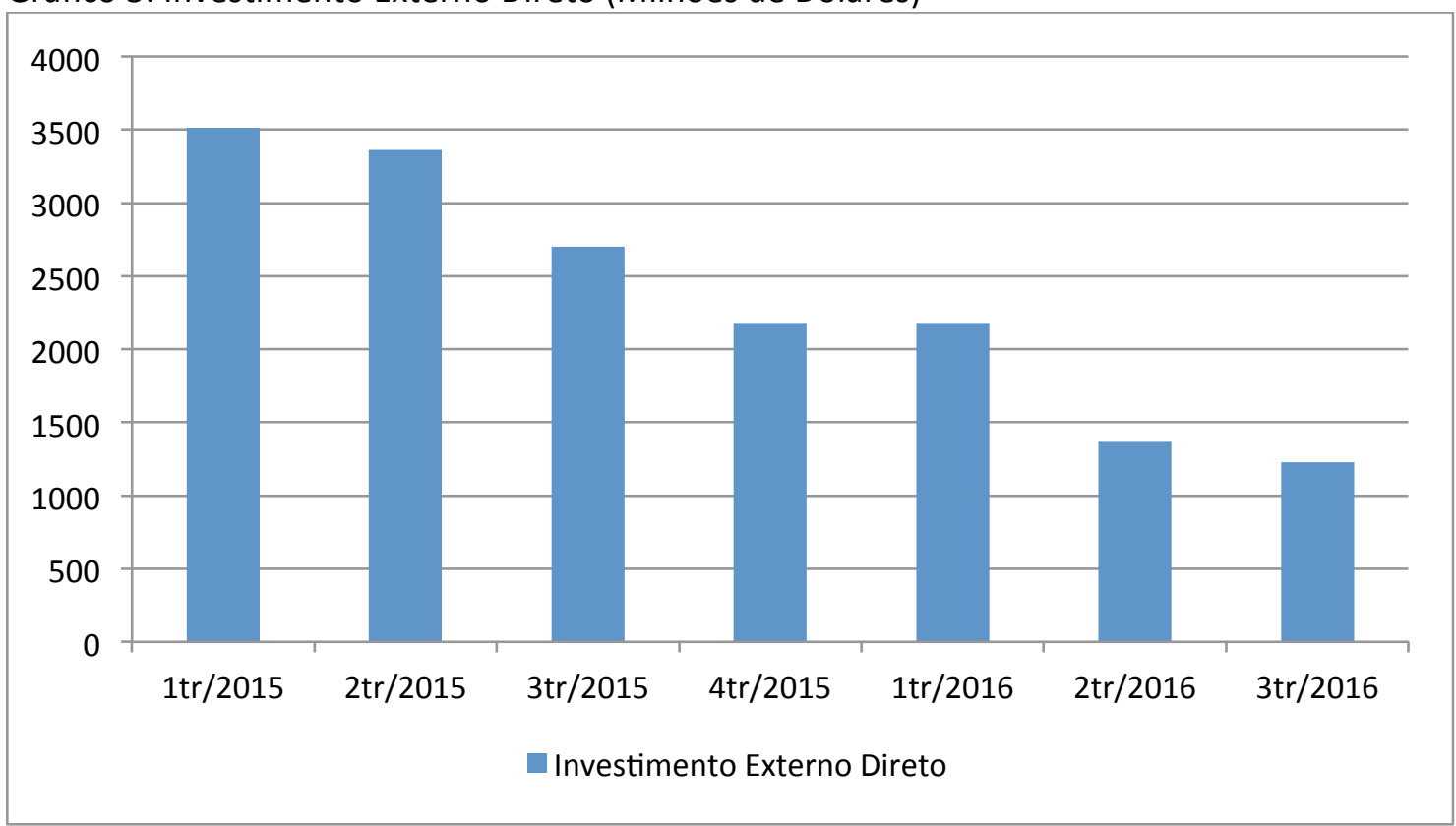

Fonte: INDEC

Por outro lado, os investimentos em portfólio, após estagnarem nos primeiros trimestres de 2015 e caírem às vésperas da eleição, obtiveram uma melhora em 2016. A liberalização do câmbio e a nova emissão de títulos no mercado internacional contribuíram para o resultado positivo. Mas, como visto acima, pouco foi o impacto sobre o investimento contrastando com os objetivos da equipe econômica. 
Gráfico 4: Investimento em Portfólio (Milhões de Dólares)

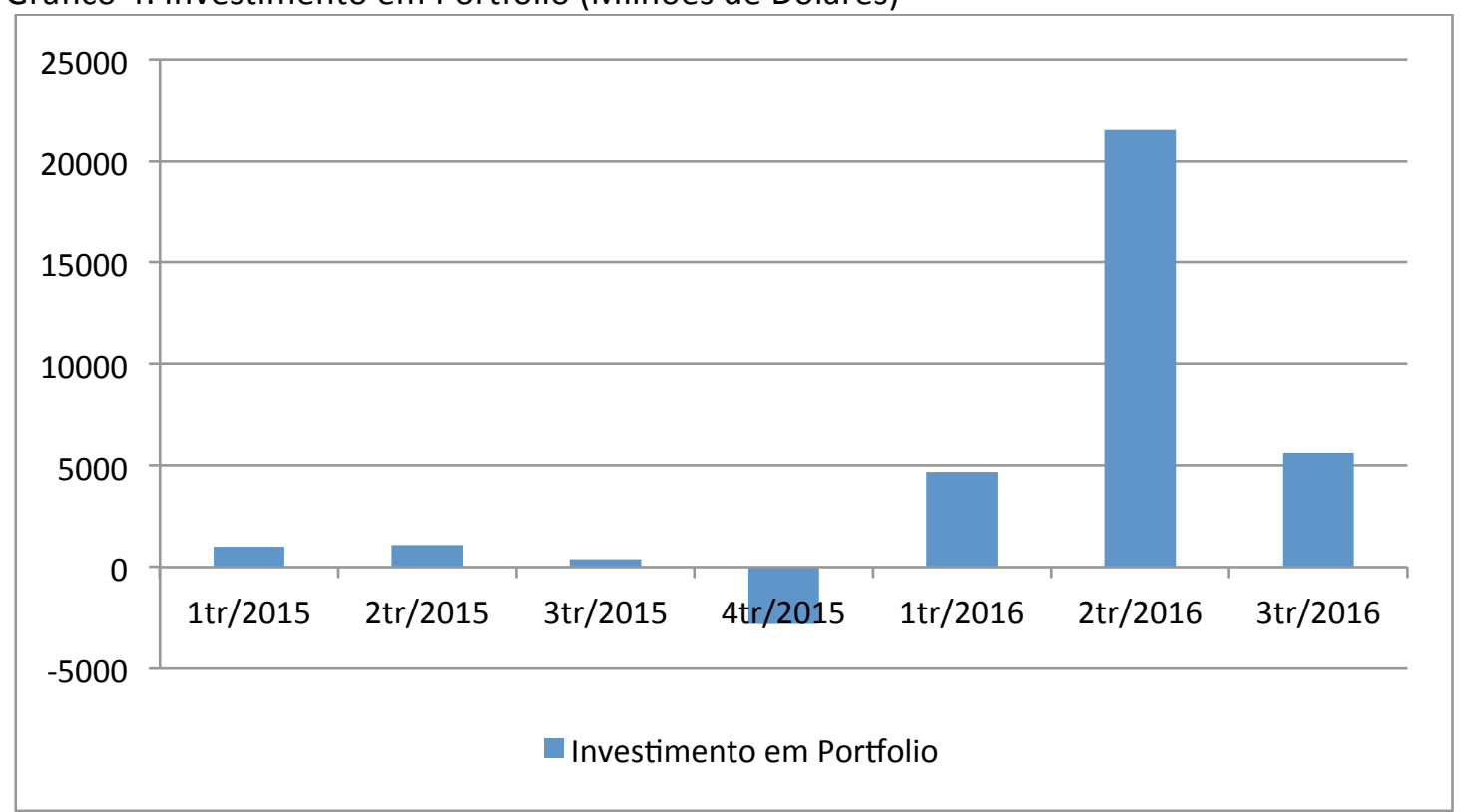

Fonte: INDEC

A inflação, uma das peças fundamentais para a construção de um "ambiente de negócio favorável", segundo as autoridades argentinas, foi um dos piores resultados do governo Macri. O ritmo de crescimento nos preços de 2016 foi mais do que $50 \%$ maior do que o resultado de 2015. Os aumentos das tarifas públicas aliadas a maxidesvalorização elevaram o patamar inflacionário no país

Gráfico 5: Inflação Anual

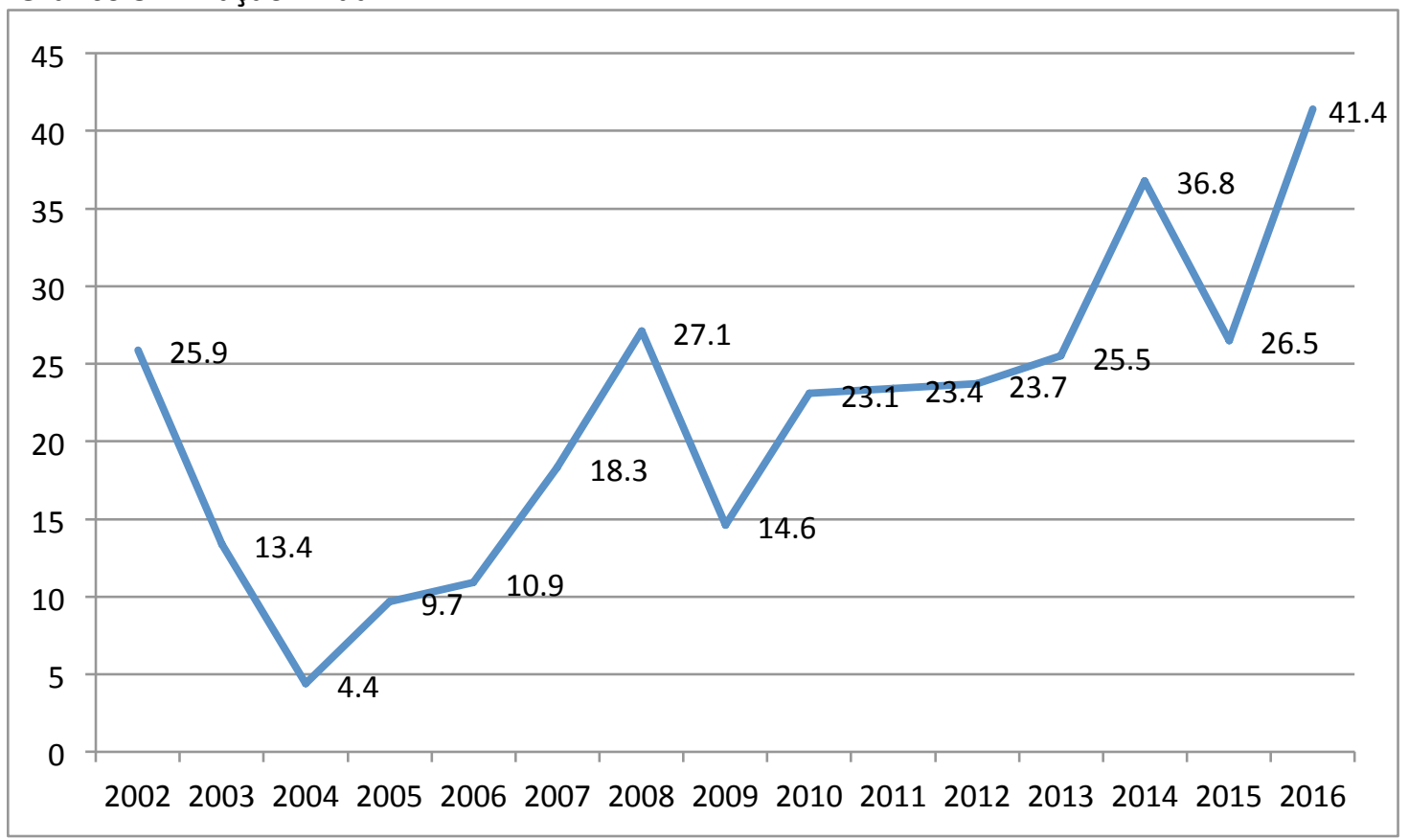

Fonte:2002-2006 (INDEC), 2007-2014 (Inflação Médias das Províncias), 2015-2016 (INDEC IPCBA)

\section{Considerações Finais}

Terminado o primeiro ano de seu mandato, o governo Macri enfrenta grandes dificuldades para resgatar o dinamismo da economia Argentina. A queda de seu ministro da fazenda no 
primeiro ano reflete o descontentamento do presidente com a gestão da economia. Porém o problema talvez não esteja somente no manejo da economia, mas sim na estratégia adotada. Um crescimento puxado pelos investimentos necessita de uma política econômica mais voltada para o "animal spirits" do que para a "fada da confiança".

\section{Referências}

Amico, F. (2013), "Crecimiento, distribución y restricción externa en Argentina", Circus, Revista Argentina de Economía, n. 5.

Barreiro, R. (2016), "Devaluación y fondos buitre, los hitos de un año de gestión Alfonso PratGay", El Pais, 26 de dezembro de 2016.

BCRA - Banco Central de la República Argentina (2016), "Informe Monetario Mensual", Outubro de 2016.

Considine, J. e Duffy, D. (2016). "Keynes and the confidence fairies" Cambridge Journal of Economics, n. 40, 309-325.

Clarin (2016), Carrió le pegó duro a Prat-Gay por pedirles perdón a los empresarios españoles, 1 ㅇ de junho de 2016.

INDEC (2015a), Cuentas Nacionales: Series trimestrales de Oferta y Demanda Globales (20042016).

INDEC (2015b), Estimación de la Posición de Inversión Internacional (Años 1991-2015).

Keynes, J. M. (1929 [1978]), Can Lloyd George Do It Again? In E. Johnson e D. Moggridge (eds.): The Collected Writings of John Maynard Keynes. Royal Economic Society.

Keynes, J. M. (1936 [1996]), A Teoria Geral do Emprego, do Juro e da Moeda. Editora Nova Cultural.

King, L., Kitson, M., Konzelmann, S. e Wilkinson, F. (2012), “Making the same mistake again or is this time different?" Cambridge Journal of Economics, 26, p.1-15.

Kulfas, M. (2014), "La economía argentina, entre la "década ganada» y los "fondos buitre»", Revista Nueva Sociedad, n.254, p.4-16.

Varesi, G. A. (2016), "Tiempos de restauración. Balance y caracterización del gobierno de Macri en sus primeros meses", Revista Realidad Económica, n.302, p.6-34.

Yebra, M. R. (2016) “Prat-Gay pidió 'perdón' a los inversores españoles por los 'abusos' del kirchnerismo", La Nacion, 30 de maio de 2016. 